\title{
Social Domain
}

National Cancer Institute

\section{Source}

National Cancer Institute. Social Domain. NCI Thesaurus. Code C121206.

A domain of the General Adaptive Composite Score that is made up of scores from social and leisure skills assessments. 